\title{
Covid-19: collateral damage of lockdown in India
}

\author{
The wider effect of India's lockdown on an already fragile healthcare system is starting to show, \\ Bhavya Dore reports
}

\author{
Bhavya Dore freelance journalist
}

Mumbai, India

On 25 March, the first day of India's nationwide lockdown, Rosemary Fernandes posted a plea on Facebook, "Seeking some help here. My mum needs to be treated (dialysis) at the hospital thrice a week. With the rickshaws etc being shut, there is no way I can help transport her to and fro. Is there anyone who can put some light on the situation?... \#SOS \#21DayLockdown."

Though essential services are supposed to be functioning, transport services have been minimal, and there was little clarity at the outset of the lockdown-now extended until 3 May-on how it was being implemented. There were reports of police brutalising people leaving their homes.

"Initially it was very difficult, especially arranging transport," Fernandes tells The BMJ. "People were concerned about lending their vehicles, in case we brought back the disease. We were struggling, but later people started coming forward to help."

India has more than 130000 patients like Fernandes's mother who need regular dialysis for kidney conditions. ${ }^{1}$ They have been among those hit by the restrictions, with the media reporting patients dying in Ahmedabad, Noida, and Delhi because they were unable to get timely care. ${ }^{2-4}$ Those requiring chemotherapy, antenatal care, or medication for conditions such as HIV and tuberculosis have also been hamstrung by the limitations. One man reportedly cycled $130 \mathrm{~km}$ with his wife to ensure she made her chemotherapy appointment. ${ }^{5}$

A Mumbai based nephrologist, who asked not to be named, says that one of his patients died because he couldn't access dialysis, but that doctors like him were helpless since many dialysis units were shut after detecting covid-19 cases. "The situation has been bad; patients have been running from pillar to post," he says. Even the operational units were functioning with fewer staff and fewer shifts. He says some units were "risking the life of the patient" by treating them twice a week rather than three times.

Since the lockdown began, hospitals have been working below capacity, with elective surgeries postponed, many outpatient departments shut, and in some cases entire hospitals closed for several days because of health workers getting infected.

India has officially recorded more than 31000 covid-19 infections and over 1000 deaths. There is no official count of deaths from other causes that are linked to the lockdown, but anecdotal evidence from media reports, doctors, and activists suggests they have been happening. Cardiac specialists, puzzled by the dip in emergency heart attack cases since the lockdown, fear that patients, afraid of getting infected, may be dying at home. $^{6}$

"This could have been avoided with more planning and better foresight," says Anant Bhan, a university professor and researcher in global health, bioethics, and health policy. "It is important to prioritise the covid response at this time, but not at the cost of other essential health services. We don't want the health system to close its doors to vulnerable patients."

\section{Business as unusual}

In Bhopal, the city where the Union Carbide gas leak killed more than 3000 people in 1984, survivors continue to live with the after effects of the disaster. On 23 March, the Bhopal Memorial Hospital and Research Centre, set up specifically to cater for such patients, was converted into a covid-19 hospital. Rachna Dhingra, who works with survivors, is scathing of the decision. "The hospital's sole objective was to provide medical care to the victims of the world's worst industrial disaster and not to kill them." She accused the hospital's management of criminal negligence, saying the hospital refused to see any gas disaster patients for 22 days on the pretext of treating only those with covid-19.

In a letter to the chair of the monitoring committee for gas relief hospitals on 10 April, she pointed out that 86 patients were discharged or referred elsewhere, and four later died at home or in other hospitals for want of proper medical care. Dhingra also says that the seven covid-19 patients who died in Bhopal had all been harmed by the gas tragedy, further highlighting the group's deep medical vulnerabilities. After one survivor went to court seeking the reopening of the hospital for gas disaster patients, the state government revoked its order on 15 April. The Bhopal hospital is now open as normal, "but it took [many] lives to get us here," says Dhingra.

At hospitals that have remained open, staff numbers are lower than usual and only essential procedures are being done. For instance, at the Asian Cancer Institute in Mumbai two doctors 
and two nurses were infected with covid-19. This meant several other workers had to be quarantined, bringing down operational staff. "Most hospitals have $30-40 \%$ of usual staff numbers, which means their ability to treat patients also comes down," says Ramakant Deshpande, the director.

He says they were avoiding long operations, surgery on older patients, and endoscopic and laparoscopic procedures-which have a higher risk of exposure to aerosols- to cut down the risk of the infection.

Where they can, doctors are postponing surgery, sending prescriptions electronically, coordinating with other hospitals, or providing a combination of alternative stop-gap measures. "Six weeks is a long period, for example, if a patient has stomach or tongue cancer and isn't treated; he can go from stage one to stage three and the cure rate can fall from $85-90 \%$ to practically half of that," says Deshpande. "We don't want our patients to lose out on chances of getting cured."

Sukumar Mehta, an Ahmedabad based cardiothoracic surgeon, says operations were "practically down to zero," with no bypass or open heart procedures since 25 March. He says those with angina pain and triple vessel coronary artery blockages would have ordinarily been advised a bypass but are being treated with non-surgical options such as balloon angioplasty and stenting, and even then only for the life threatening blockages. Mehta told The BMJ that he had performed one bypass at the end of April following protocols on using personal protective equipment (PPE) and after testing the patient for covid-19. The extra costs for the protective equipment and testing are passed on to the patients in private hospitals.

Pregnant women and infants are another vulnerable group. "Our health system is already at capacity. And with lack of access to transport and functioning hospitals in the current crisis pregnant women do not know where to access care when there is an emergency," says Aparna Hegde, an associate professor of urogynaecology and founder of a non-profit organisation that works on child and maternal health in 16 states. "We are trying our best to guide women using virtual solutions like our virtual outpatient department."

\section{Policing a problem not solution}

On 17 April, at a daily health ministry briefing, joint secretary Lav Agarwal said the ministry had issued detailed guidelines for non-elective surgery and medical interventions. ${ }^{7} \mathrm{He}$ said, "Other hospitals should provide services, whether for TB, HIV, dialysis, maternal health, cardiac, or hepatitis patients."

The guidelines mention various measures, including doing infant check-ups at home and delivering medicines, and that states should "ensure uninterrupted availability of dialysis and cancer treatment services" and facilitate "easy movement of these patients to access care." $"$

There is a pass system that allows travel for a valid medical reason-people can apply online or at their local police station depending on the jurisdiction's rules. But logistical issues remain, and interpretation of the rules by police varies.

"Even if you have functional hospitals, how do you get there?" says Bhan. "All [government] departments need to be involved, not just health related ones. Not everyone has access to the online system and so much depends on the cooperation of the police."
The practicalities have hobbled blood donations too. India has 3321 licensed blood banks and a well documented gap between demand and availability, even in normal times. ${ }^{8}$

"There are passes for essential service workers, but our donors need a one-time pass," says entrepreneur Balu Nayar, who founded the volunteer led Twitter account @BloodDonorsIn, connecting 1.21 million followers to patients needing blood. "[We ask them to go] with letters from the hospitals, but it all depends on the police officer on the ground allowing it. Sometimes it works, sometimes it doesn't."

\section{Shortages}

Doctors are concerned about a shortage of some medicines, PPE, and equipment. "While covid hospitals of course need support in terms of PPE, non-covid hospitals are facing the brunt of the PPE shortage as PPE is needed for emergency surgeries like caesarean sections," says Hegde. "Due to a combination of factors such as inordinately increased demand all around, inadequate production, supply chain disruption, and lack of specific funding support for non-covid hospitals, there is a significant shortage of much needed PPE."

The knock-on effects of lockdown on imported equipment is also a concern for the coming months. "The stock of dialysis equipment is depleting, and new material has not been able to reach [its destination]," says Sudhiranjan Dash, a Mumbai based nephrologist. Dash fears the crisis will affect procurement from abroad. "Without this, we may have to re-use existing equipment," he tells The BMJ.

People with pre-existing conditions are also likely to be more vulnerable to covid-19, which means everyone has to be additionally vigilant. "We must ensure continuity of care (prevention, diagnostics, treatment and follow-up) for people with underlying conditions," Farah Naz Hossein, a medical coordinator for MSF India, told the BMJ. "We must take all necessary steps to ensure that the impact of this pandemic does not create additional tragedies."

Competing interests: I have read and understood BMJ policy on declaration of interests and have no relevant interests to declare.

Provenance and peer review: Commissioned; not externally peer reviewed.

1 Hafeeq B, Gopinathan JC, Aziz F, etal . The expanding role of "stand-alone" hemodialysis units in chronic renal replacement therapy: a descriptive study from North Kerala. Indian $J$ Public Health 2019;63:157-9. 10.4103/ijph.IJPH 288 1831219068

2 Ahmedabad: Patient with kidney trouble dies as hospital closes ICU. Times of India 2020 Apr 16. https://timesofindia.indiatimes.com/city/ahmedabad/patient-with-kidney-troubledies-as-hospital-closes-icu/articleshow/75169933.cms

3 Salaria S. Noida: Dialysis patient told to get covid-19 test first, dies. Times of India 2020 Apr 18. https://timesofindia.indiatimes.com/city/noida/noida-dialysis-patient-told-to-getcovid-19-test-first-dies/articleshow/75212905.cms

4 Dialysis patient denied treatment in Delhi, dies. Indian Express 2020 Apr 16. https://www. newindianexpress.com/cities/delhi/2020/apr/16/dialysis-patient-denied-treatment-dies2130804.html

5 Dominique B. Tamil Nadu man cycles $130 \mathrm{~km}$ with wife to give her cancer care on time. Time of India $2020 \mathrm{Apr} 20$. https://timesofindia.indiatimes.com/city/puducherry/tamil-naduman-cycles-130-km-with-wife-to-give-her-cancer-care-on-time/articleshow/75090631.cms

6 Harkut P. Where are missing heart attack patients? 11 Apr 2020. https://thelivenagpur. com/2020/04/11/where-are-missing-heart-attack-patients/

7 Enabling delivery of essential health services during the covid-19 outbreak: guidance note. 13 Apr2020. https://www.mohfw.gov.in/pdf/

EssentialservicesduringCOVID19updated0411201.pdf

8 Ministry of Health and Family Welfare. Questions to health minister. No 4585. Blood bank infrastructure, 20 Mar 2020. http://164.100.24.220/loksabhaquestions/annex/173/AU4585. pdf

Published by the BMJ Publishing Group Limited. For permission to use (where not already granted under a licence) please go to http://group.bmj.com/group/rights-licensing/ permissions 